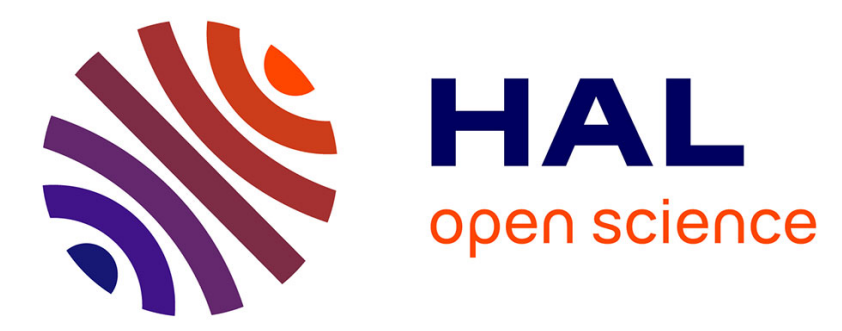

\title{
Blonde Like Me: When Self-Construals Moderate Stereotype Priming Effects on Intellectual Performance
}

Clémentine Bry, Alice Follenfant, Thierry Meyer

\section{To cite this version:}

Clémentine Bry, Alice Follenfant, Thierry Meyer. Blonde Like Me: When Self-Construals Moderate Stereotype Priming Effects on Intellectual Performance. Journal of Experimental Social Psychology, 2008, 44 (3), pp.751. 10.1016/j.jesp.2007.06.005 . hal-00582710

\section{HAL Id: hal-00582710 https://hal.science/hal-00582710}

Submitted on 4 Apr 2011

HAL is a multi-disciplinary open access archive for the deposit and dissemination of scientific research documents, whether they are published or not. The documents may come from teaching and research institutions in France or abroad, or from public or private research centers.
L'archive ouverte pluridisciplinaire HAL, est destinée au dépôt et à la diffusion de documents scientifiques de niveau recherche, publiés ou non, émanant des établissements d'enseignement et de recherche français ou étrangers, des laboratoires publics ou privés. 


\section{Accepted Manuscript}

Blonde Like Me: When Self-Construals Moderate Stereotype Priming Effects on Intellectual Performance

Clémentine Bry, Alice Follenfant, Thierry Meyer

PII:

S0022-1031(07)00094-7

DOI:

10.1016/j.jesp.2007.06.005

Reference:

YJESP 2005

To appear in:

Journal of Experimental Social Psychology

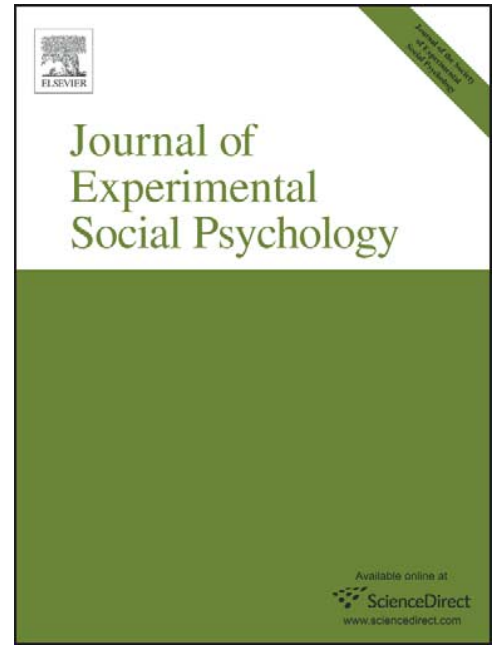

Received Date: $\quad 9$ February 2007

Revised Date: $\quad 17$ June 2007

Accepted Date: $\quad 18$ June 2007

Please cite this article as: Bry, C., Follenfant, A., Meyer, T., Blonde Like Me: When Self-Construals Moderate Stereotype Priming Effects on Intellectual Performance, Journal of Experimental Social Psychology (2007), doi: 10.1016/j.jesp.2007.06.005

This is a PDF file of an unedited manuscript that has been accepted for publication. As a service to our customers we are providing this early version of the manuscript. The manuscript will undergo copyediting, typesetting, and review of the resulting proof before it is published in its final form. Please note that during the production process errors may be discovered which could affect the content, and all legal disclaimers that apply to the journal pertain. 
Running head: SELF-CONSTRUALS IN PRIME-TO-BEHAVIOR EFFECTS

Blonde Like Me: When Self-Construals Moderate Stereotype

Priming Effects on Intellectual Performance.

Clémentine Bry, Alice Follenfant, and Thierry Meyer

Université Paris X - Nanterre

Correspondence should be send to first author: clementine.bry@u-paris10.fr

Word number: 4237 


\begin{abstract}
Stereotype priming can lead to assimilation or contrast effects on behavior. We argue that self-activation is a moderator of both assimilation and contrast effects. To test this hypothesis, in two studies, we activated independent or interdependent self-knowledge before priming participants with the dumb Blonde stereotype or a control category (Study 1) or no prime (Study 2). Participants then answered a knowledge test. Results support our expectations: Participants presented assimilation under interdependence (i.e., underperformance compared to control group) while they presented no assimilation (i.e., comparable performance with control group in Study 1) and contrast (better performance than control group in Study 2) under independence. We discuss implications of these findings in regards of previous research and recent models such as the Active Self Account (Wheeler, DeMarree, \& Petty, 2005).
\end{abstract}

Keywords: prime-to-behavior effects, automatic behavior, priming, self-construal, Blonde stereotype, independence, interdependence, assimilation, contrast 
Blonde like me: When self-construals moderate stereotype priming effects on intellectual performance

An extensive body of literature has demonstrated that increasing accessibility of stored knowledge can influence subsequent behavior (for a review, see Wheeler \& Petty, 2001). These prime-to-behavior effects concern a large set of behaviors like motor action (e.g. Bargh, Chen, \& Burrows, 1996; Follenfant, Légal, Marie Dit Dinard, \& Meyer, 2005), intellectual performance (e.g. Dijksterhuis \& Van Knippenberg, 1998), creativity (Förster, Friedman, Butterbach, \& Sassenberg, 2005), helping behavior (Macrae \& Johnston, 1998), or competition (Kay, Wheeler, Bargh, \& Ross, 2004). In the present study, we focus on the effects of stereotype activation on intellectual performance. For instance, Dijksterhuis and van Knippenberg (1998, exp.1) showed that participants primed with the stereotype of professors subsequently had better performance on a knowledge test compared to control conditions (i.e., secretaries or no stereotype). They concluded that assimilation effects previously obtained on motor behavior (Bargh et al., 1996) could be extended to complex intellectual behavior. The aim of the present study is to further investigate whether selfconstruals (Markus \& Kitayama, 1991) can moderate prime-to-behavior effects. In two experiments, we expected a behavioral assimilation effect under interdependence and a behavioral contrast effect under independence.

Priming effects can have two consequences: Behavior may be either displaced toward (assimilation) or away (contrast) from the prime. Thus, one generally refers to assimilation when priming a concept (e.g., elderly stereotype) leads to corresponding behavior in the perceiver (e.g., walking slowly), and to contrast when it leads to inverse behavior in the perceiver (e.g., walking fast). Assimilation is often considered as the default option (see Biernat \& Manis, 2007). It is true that the priming paradigm most frequently elicits assimilation (see Wheeler \& Petty, 2001), whereas contrast effects tend to occur only in the 
presence of specific factors like exemplar priming or self-activation (Dijksterhuis et al., 1998; Dijksterhuis \& van Knippenberg, 2000). However, we consider that effects of priming on behavior should be assessed only when compared with a control condition and not when compared to another experimental condition. Without such a control condition, one cannot determine where the action is: A behavioral difference between two experimental conditions does not mean that there are two effects (e.g., assimilation and contrast), but perhaps that there is just one effect (assimilation or contrast) versus no effect (i.e., equivalent to a control condition). Although several studies have shown behavioral assimilation effects compared to a control condition (Bargh, et al., 1996; Macrae \& Johnston, 1998), behavioral contrast effects are usually shown relative to an assimilation effect and not relative to a control condition (e.g., Dijksterhuis, et al., 1998). We believe that an assimilation effect can be said to occur only when behavior moves toward the prime and is significantly different from a control or no prime condition. Conversely, there is a contrast effect when behavior moves away from the prime and is significantly different from a control or no prime condition (Wheeler \& Suls, 2007).

Not all prime-to-behavior effects can be explained by direct perception-behavior links (Bargh et al., 1996), or by indirect link mediated by trait activation (Dijksterhuis \& Van Knippenberg, 1998). Indeed, these mechanisms would predict only assimilation but not contrast effects. Rather, we argue in favor of prime-to-behavior effects moderated by selfconcept. Assimilation would occur when self-concept is congruent with the prime. Contrast would occur when self-concept is incongruent with the prime. Several researchers have investigated how self-concept could influence priming effects (e.g., Dijksterhuis \& van Knippenberg, 2000; Hull, Slone, Meteyer, \& Matthews, 2002).

Recently, Schubert and Häfner (2003 exp.2) investigated the influence of selfactivation on prime-to-behavior effects. Participants were primed with a category linked to 
high (i.e., professor) or low intelligence (i.e., hussy), while flashed with self-related or otherrelated words prior to answering a general knowledge test and rating their perceived intelligence. Participants flashed with other-related words presented congruent performance with primes: Professor-primed participants marginally performed better than hussy-primed participants. Participants flashed with self-related words presented incongruent performance with primes: Professor-primed participants performed worse compared to hussy-primed participants. Additionally, intelligence self-ratings were consistent with behavioral performance. Self-activation produced prime-incongruent self-ratings while other-activation produced prime congruence self-ratings. Consistent with our assumption, priming influences both self-concept and behavior (See also Dijksterhuis et al., 1998).

Schubert and Häfner argued that self-activation triggered contrast effects. However, from our point of view, the absence of a control condition does not unequivocally show contrast effect (See also Dijksterhuis \& van Knippenberg, 2000). Other papers indeed included a control condition when studying self-activation effects. Wheeler, Jarvis and Petty (2001) asked participants to write an essay about a student to prime Black or White stereotype. Participants next completed a math test. Participants primed with the Black stereotype subsequently performed worse compared to those primed with the White stereotype. However, a number of participants spontaneously put themselves in the shoes of the student using I-pronoun (vs. He-pronoun) when writing the essay. Additional analyses revealed that only participants who took an I-point of view presented the Black stereotype effects. In this paper, assimilation occurred under self-activation, with a paradigm that included a control condition but did not include a manipulation of self-activation (see also Hull et al., 2002).

As far as we know, no study concerning prime-to-behavior effects has shown that self-activation can lead to assimilation and contrast, by comparison to a control condition, 
with the same prime, within the same study. Knowing whether self-activation can lead to both types of effects (i.e., assimilation and contrast) can contribute to our understanding of the underlying mechanisms of prime-to-behavior effects. Indeed, if prime-to-behavior effects are moderated by self-activation, the direct perception-behavior link would be questioned. In this case, another mechanism should be considered, for instance as proposed in the Active Self Account developed by Wheeler, DeMarree and Petty (2005). The Active Self Account proposes that behavioral assimilation to the prime follows from inclusion of prime features in the self-perception while contrast follows from inclusion of prime-incongruent features and exclusion of prime-congruent features in the self-perception (see also DeMarree, Wheeler, \& Petty, 2005). Independent and interdependent self-construals could determine respectively exclusion and inclusion of target features in the self-perception (Gardner, Gabriel, \& Hochschild, 2002; Stapel \& Koomen, 2001). As such, in this paper, we tested whether selfconstruals moderate both behavioral assimilation and contrast.

People can construe their self as independent or interdependent (Markus \& Kitayama, 1991). When independent, people consider themselves as being unique, autonomous, and distinct from others. They define themselves using personal, internal, and abstract features like traits, abilities, and attitudes. When interdependent, people consider themselves as being connected to others, a part of a whole. They define themselves using their social relationships, memberships, and roles (Gardner, Gabriel, \& Lee, 1999; Trafimow, Triandis, \& Goto, 1991). Culture and gender generally determine a chronic self-construal (Cross \& Madson, 1997; Gabriel \& Gardner, 1999; Markus \& Kitayama, 1991). People from individualistic society and males have a relatively more independent self-construal while people from collectivist society and females have a more interdependent self-construal. Nevertheless, both construals are available in memory and can be primed by situational cues 
and social demands (Brewer \& Gardner, 1996; Kühnen \& Hannover, 2000; Trafimow et al., 1991).

Self-construals determine a large set of emotional, cognitive, and behavioral processes (Markus \& Kitayama, 1991). For instance, interdependent people rate themselves as being more similar to others than independent persons (Kühnen \& Hannover, 2000). Stapel and Koomen (2001) showed that, compared to a control-self condition, interdependents tend to assimilate their self-evaluation to a comparison source while independents tend to contrast their self-evaluation away from the source (see also Gardner et al., 2002; White et al., 2005). Moreover, self-construals moderate the chameleon effect (Chartrand \& Bargh, 1999): Compared to a control-self condition, interdependence enhances imitation tendency while independence decreases imitation tendency (Van Baaren, Maddux, Chartrand, de Bouter, \& Van Knippenberg, 2003).

Considering the literature reviewed above, we designed two studies in which we first activated an independent or interdependent self-construal and then the dumb Blonde stereotype or a control prime before measuring encyclopedic knowledge performance. We predicted that activation of interdependence would lead to assimilation to the Blonde stereotype (i.e., performance decrease) while activation of independence would lead to contrast from the Blonde stereotype (i.e., performance increase) relative to control condition.

\section{Study 1}

\section{Method}

The experiment was conducted on the Internet following guidelines on ethics and laws (APA, 2002; Caverni, 2007).

\section{Participants and design}

One-hundred and eight Internet surfers connected to the experiment website. Twentytwo participants dropped out mid-study (seven during self-construal manipulation task, six 
during stereotype priming and nine during the general knowledge questionnaire). Drop-outs were equivalent in all experimental conditions. The final sample consisted of 86 participants (61 women, 23 men and 2 unknown; $M_{\text {age }}=23.33, S D_{\text {age }}=6.27$ ) randomly assigned to one of the four conditions of a 2 (self-construal: independence vs. interdependence) $\times 2$ (primed category: Blondes vs. control) between-subjects design.

\section{Procedure and stimulus materials}

Participants were recruited on Internet newsgroups through advertising messages. These messages invited Internet surfers to participate in 3 different psychology studies conducted by researchers from the University of Paris X. These studies were presented as concerned with personality, color perception and general knowledge. Before connecting to the website, surfers had to ask for a password. A personal and unique password was given, controlling for multiple submissions, in order to guard against multiple participations (Reips, 2002). Once connected, participants received an electronic consent form providing general information about studies and instructions about participation (e.g., anonymity and confidentiality, possibility to interrupt the experiment at every moment by clicking on "exit", "how to use the website" rules). Participants either clicked on 'I agree to participate' which led to the first task or on 'I refuse' which led to an exit page thanking participants for their interest.

The first task presented to participants as a personality questionnaire was our selfconstrual manipulation. Seven items (from the meta-analysis by Oyserman, Coon and Kemmelmeier, 2002, p. 9, table 1) were presented twice (i.e., first about work and then about leisure situations) and participants had to evaluate how well each item described them on a 7point scale $(1=$ not at all to $7=$ absolutely $)$. In the independence condition, participants were presented with the seven items related to independence (e.g., "I tend to do my own thing, and others do the same"; "I am unique-different from others in many respects"). In the 
interdependence condition, participants were presented with seven out of the eight items related to interdependence (e.g., "to understand who I am, you must see me with members of my group"; "to me, pleasure is spending time with others"). Furthermore, we biased each item with the adverb 'sometimes' (e.g., I sometimes tend to do my own thing and others do the same). This procedure leads participants to agree more with the items and admit only one kind of self-knowledge as self-descriptive (Chaiken \& Baldwin, 1981).

Next participants were presented with the second task, the color perception task, designed to activate a category stereotypically associated with stupidity. We chose the dumb blond female stereotype which is widely spread in France through the media (e.g., Gibaja \& Mimran, 2006; Guéro \& Dzack, 2005; Luketic, 2001). Blondes are usually associated with both low intelligence and ability and high beauty and femininity. We ensured those features were associated to Blondes in a pilot study. Eleven students listed the most common characteristics associated with Blondes: $40 \%$ of listed adjectives referred to stupidity and $36 \%$ were linked to seduction and beauty. Only one participant did not check off stupidity as a Blonde's features.

In order to activate the Blonde stereotype, participants were exposed to 30 facepictures and had to indicate each person's hair color on a four-point color scale (i.e., black, brown, blond and red). In the Blonde stereotype condition, there were 21 pictures of nonambiguously blond beauty queens, and nine of dark-haired beauty queens (brown, black or red). In the control category condition, there were 21 pictures of dark-haired men and nine of blond ones. We chose men as a control prime because we reasoned that this category is not particularly associated with high or low encyclopedic knowledge. The men category should not influence participants' performance. Pictures were randomly chosen between a large set of pictures and presented in a random order. Each participant was primed with a different collection of pictures. All pictures were front-faced on a white background. 
The third task was an encyclopedic knowledge test intended to give an index of intellectual performance (see Dijksterhuis \& Van Knippenberg, 1998). We selected one hundred questions of diverse fields of knowledge from the Trivial Pursuit game (1993). We transformed them into three response-option questions (only one correct answer) and submitted them to a pilot study on the Internet $(N=7590)$. We considered four difficulty levels of questions as a function of quartiles for correct answers. In the present experiment, our knowledge test included five questions of each difficulty level, randomly chosen and ordered from the whole sample of questions. We expected some effects of our variables on the moderately difficult questions (i.e., about 1.99 correct answers out of 5 questions on the pilot study) because they appear to be the most sensitive (performance on other questions might be limited by ceiling or floor effects). Participants were asked to select the correct answer among the three options, with no time pressure but alone and without any help (i.e., no encyclopedia and no web search).

After knowledge test fulfillment, participants answered a set of questions to ensure they were not aware of our hypotheses and not suspicious of any link between the three tasks. Finally, participants were fully debriefed through a text presenting the whole experiment and hypotheses.

Results and discussion

We submitted the number of correct answers on the five moderately difficult questions 1 to a 2 (self-construal: independence vs. interdependence) $\times 2$ (primed category: Blondes vs. control) ANOVA. We only found a significant interaction ${ }^{2}, F(1,82)=5.77, p<$ $.02, \eta_{\mathrm{p}}^{2}=.066$. Interdependence-Blonde primed participants $(M=1.14, S D=0.86)$ performed worse compared to interdependence-control primed participants $(M=1.93, S D=$ $1.11, F(1,82)=4.82, p<.04)$. Independence-Blonde primed participants $(M=1.90, S D=$ 1.29) performed as well as those in the independence-control condition $(M=1.5, S D=0.73$, 
$F(1,82)=1.38, n s)$. The independence-control group $(M=1.5, S D=0.73)$ obtained similar performance to the interdependence-control group $(M=1.93, S D=1.11, F(1,82)=1.55$, $n s)$.

Consistent with our predictions, we found an assimilation effect to the Blonde stereotype among interdependence-primed participants: Performance was lower than after interdependence-control priming. However, the contrast effect - expected among participants primed with independence and the Blonde stereotype - did not occur. Performance was equivalent with those in the control condition. Thus, only participants primed with interdependence showed prime-to-behavior effects.

Study 2

In Study 1, experimental and control primes differed on both gender and hair color. This variable confusion might weaken our conclusions. We designed Study 2 to replicate Study 1 with a no prime control condition. Furthermore, we conducted Study 2 in lab conditions.

Method

Participants and design

Seventy-three volunteers (34 men, 39 women, $\left.M_{\text {age }}=25.14, S D_{\text {age }}=10.94\right)$ were randomly assigned to one of the four conditions of a 2 (self-construal: independence vs. interdependence $) \times 2$ (Blonde stereotype: activated vs. not activated) between-subjects design.

\section{Procedure and stimulus materials}

Participants were recruited on the street to participate in a study, in exchange of a free drink. The study was presented as concerned with concentration effects on performance and run by the Haute-Bretagne University. Participants followed the recruiter to a lab, where the (female) experimenter offered them a drink and settled them in a room where up to 15 
persons filled in different questionnaires (the same room was used to run several different studies). Next, she gave them a questionnaire and, depending on condition, a photo booklet (or not) to use during the distractive task. She explained the questionnaire contained all the instructions about the concentration task, the distraction task (or not), and the encyclopedic knowledge test.

The concentration task, that manipulated self-construal, was the same used in Study 1, but in a paper-and-pencil version.

The distraction task allowed to activate the dumb Blonde stereotype. The priming procedure was a paper-and-pencil version of the one used in Study 1. Participants examined face-pictures of 30 beauty queens gathered in the photo booklet ( 21 blond and 9 dark-haired women). They had to report each person's hair color on a separate grid. Participants did not complete the distraction task in the 'no activated stereotype' condition.

The encyclopedic knowledge test measured an intellectual performance with a part of the questions used in Study 1. It included five moderately difficult questions (i.e., about 2.24 correct answers out of 5 questions on the pilot study) and five moderately easy questions (i.e., about 3.56 correct answers out of 5 questions on the pilot study). Questions were in a random fixed order. Participants had to circle the correct answer among the three options.

Next, participants answered a set of questions to ensure they were not aware of our hypotheses and of the link between the three tasks. They were finally thanked and debriefed. Results and discussion

We submitted the number of correct answers to moderately difficult questions ${ }^{3}$ to a 2 (self-construal: independence vs. interdependence) $\times 2$ (Blonde stereotype: activated vs. not activated) ANOVA. We only found a significant interaction effect ${ }^{4}, F(1,69)=12.82, p<$ $.001, \eta_{\mathrm{p}}{ }^{2}=.16$. Interdependence-blonde primed participants $(M=1.52, S D=0.90)$ underperformed interdependence-control primed participants $(M=2.17, S D=0.73 ; F(1,69)$ 
$=5.33, p<.03)$. Independence-blonde primed participants $(M=2.37, S D=0.96)$

outperformed independence-control primed participants $(M=1.53, S D=0.94 ; F(1,69)=$

$7.50, p<.01)$. Independence-control primed participants $(M=1.53, S D=0.94)$

underperformed interdependence-control primed participants $(M=2.17, S D=0.73, F(1,69)$

$=4.53, p<.04)$.

Consistent with Study 1, assimilation to the Blonde stereotype occurred under interdependence priming: Performance was lower than in the control condition. Moreover, the expected contrast effect occurred under independence priming: Performance was higher in the Blonde condition than in the control condition. These results provide support for the prediction that both assimilation and contrast can occur within the same study and to the same prime, according to the current self-construal. We did not expect the effect of selfconstruals on performance in control conditions but findings tell another story: Independence-primed participants performed worse than interdependence-primed participants. It seems that activation of independent self-construal can lead to lower knowledge performance. This effect was not significant in Study 1 but in Study 2, the immediate connection between self-construal manipulation and the performance test enhanced the construal effect. Still, interdependent participants are not more intelligent than independent participants. We think that self-construals influenced processes that might play a role in encyclopedic knowledge retrieval. Indeed, independence promotes contextindependence processes like focal attention and inhibition of seemingly irrelevant cues whereas interdependence promotes context-dependence processes as broad attention and weak inhibition (Hannover, Pölhmann, \& Springer, 2005). It is conceivable that recalling encyclopedic knowledge requires a rather context-dependent cognitive style (i.e., less inhibition to explore widely the mental network) that disadvantaged independent-primed 
participants. This is a new and promising line of research for both self-construals and primeto-behavior.

\section{General discussion}

In two studies, we investigated self-construal moderation of the Blonde stereotype effects on encyclopedic knowledge performance. After self-construal manipulation, participants were primed with the dumb Blonde stereotype or a control category in Study 1 or not primed in Study 2. In both experiments, only participants primed with interdependence demonstrated an assimilation effect: They performed worse on the knowledge test after the dumb Blonde stereotype priming than after control or no priming. We obtained the opposite effect with an independent self-construal: Participants performed better after the Blonde priming than after control or no priming. However, the expected contrast effect occurred only in the second study.

These findings extend previous research on prime-to-behavior effects and selfconstruals, notably those of Schubert and Häfner (2003). Our findings provide further evidence for Schubert and Häfner's hypothesis. We replicated their "contrast" effect following independence priming in a paradigm that included a control condition. Moreover, the present study extends Schubert and Häfner findings by showing an assimilation effect after self-activation. Self-activation does not always trigger behavioral contrast but can also enhance assimilation depending on the activated self-concept. This malleability of prime-tobehavior effects after self-activation supports our assumption that direct links between perception and action cannot account for these effects, at least for encyclopedic knowledge kind of task used in the present studies. Additionally, we replicated the assimilation effect found by Wheeler et al. (2001) and by Hull et al. (2002) in a paradigm that included a manipulation of self-activation. 
Our reasoning was partly based on the Active Self Model developed by Wheeler et al. (2005). The Active Self Model posits that priming influences the self-concept either in a prime-congruent or incongruent manner and that behavior follows the self-concept, leading to assimilation and contrast effects, respectively. In their empirical test of this model, DeMarree et al. (2005) only demonstrated an assimilation effect, among low self-monitor participants. Our paper completes the latter, demonstrating assimilation and contrast to the same prime. However, our studies lack self-perception measures necessary to test a mediation of behavioral priming effects via self-representation. The inclusion of self measures would allow to assess more directly the underlying mechanisms of prime-to-behavior effects. Future research should address this.

Other mechanisms can also be considered. Van Baaren et al. (2003) have findings that concur with ours but they argue in favor of a mechanism based on context-dependence. Independents seem to be less "sensitive" to situational variations than interdependents (Kühnen \& Oyserman, 2002). Indeed, van Baaren and colleagues found more mimicry under interdependence self-construal and less mimicry under independence self-construal. Can context-dependence account for our findings, better than the Active Self Model? The contextdependence mechanism would imply the Blonde stereotype was activated only among interdependence-primed participants, not among independence-primed ones. In line with this reasoning, in Study 1, independence-blonde primed participants displayed neither assimilation nor contrast effect. However, in Study 2, independence-primed participants displayed a contrast effect, which implies they were influenced by the stereotype. Thus a mere context-dependence explanation cannot fully account for our results. However, we admit that both mechanisms could interact to modulate prime-to-behavior effects. Contextdependence could enhance the influence of the prime on the self-concept while contextindependence would decrease the influence of the prime on the self-concept. As such, an 
assimilation effect would occur when the prime is processed and included in the self-concept. A contrast effect would occur when the prime is processed but excluded from the selfconcept. However, priming should not influence behavior whenever the prime is not processed, for instance under a context-independent cognitive style (Kühnen \& Oyserman, 2000). Context-dependence and self-perception mechanisms could be integrated to predict and explain prime-to-behavior effects.

Stapel and van der Zee (2006) developed a Self Salience Model of other-to-self effects that considers different predictions according to the self-construal level. This model, though focused on evaluative outcomes more than on behavioral ones, has implications for prime-to-behavior effects. Our findings support this model in a standard prime-to-behavior paradigm. As such, our research contributes to the literature about self-construals, supporting the Self Salience Model, and about prime-to-behavior effects, extending this model to behavioral outcomes ${ }^{5}$.

If our account of prime-to-behavior is correct, one may wonder why Bargh et al. (1996) and others found main assimilation effects of primes. Indeed, most of these studies were conducted in individualistic cultures (i.e., the US), then contrast should have emerged rather than assimilation. However, studies are also generally conducted with mostly women and/or psychology students which are groups known to be more interdependent than the average population (Gabriel \& Gardner, 1999, Cross \& Madson, 1997). That is, participants in these studies might have been mostly interdependent. As a result, assimilation occurred. Consistent with this analysis, it is worth noting that usually priming studies involving a moderator (e.g., level of prejudice, Brown et al., 2003, Kawakami et al., 1998; degree of contact with the social group, Dijksterhuis et al., 2000; self-focus, Dijksterhuis \& van Knippenberg, 2000; self-prime comparability, Aarts \& Dijksterhuis, 2002) show no main effect of the prime. 
To conclude, our studies demonstrate that self-construals can moderate assimilation and contrast in prime-to-behavior effects. Based on the findings in social comparison research and the Active Self Model, we argued that this moderation follows a primecongruent or incongruent self-perception. However, self-construals also differ on contextdependence degree which could partly account for our findings. Future research should provide evidence of mediation of prime-to-behavior effects by self-perception. 


\section{References}

APA. (2002). Ethical principles of psychologists and code of conduct. American Psychologist, 57, 1060-1073.

Bargh, J. A., Chen, M., \& Burrows, L. (1996). Automaticity of social behavior: Direct effects of trait construct and stereotype activation on action. Journal of Personality and Social Psychology, 71, 230-244.

Biernat, M., \& Manis, M. (2007). Stereotypes and Shifting Standards: Assimilation and Contrast in Social Judgment. In D. A. Stapel \& J. Suls (Eds.), Assimilation and contrast in social psychology (pp. 75-97). New York: Psychology Press.

Brewer, M. B., \& Gardner, W. (1996). Who is this "we"? Levels of collective identity and self representations. Journal of Personality and Social Psychology, 71, 83-93.

Caverni, J.-P. (2007). Code de conduite des chercheurs en sciences du comportement [Ethical guideline for researchers in behavioral sciences]. Société Française de Psychologie from http://www.sfpsy.org/spip.php?article19.

Chaiken, S., \& Baldwin, M. W. (1981). Affective-cognitive consistency and the effect of salient behavioral information on the self-perception of attitudes. Journal of Personality and Social Psychology, 41, 1-12.

Chartrand, T. L., \& Bargh, J. A. (1999). The chameleon effect: The perception-behavior link and social interaction. Journal of Personality and Social Psychology, 76, 893-910.

Cross, S. E., \& Madson, L. (1997). Models of the self: Self-construals and gender. Psychological Bulletin, 122, 5-37.

DeMarree, K. G., Wheeler, S. C., \& Petty, R. E. (2005). Priming a new identity: Selfmonitoring moderates the effects of nonself primes on self-judgments and behavior. Journal of Personality and Social Psychology, 89, 657-671. 
Dijksterhuis, A., Spears, R., Postmes, T., Stapel, D. A., Koomen, W., van Knippenberg, A., et al. (1998). Seeing one thing and doing another: Contrast effects in automatic behavior. Journal of Personality and Social Psychology, 75, 862-871.

Dijksterhuis, A., \& Van Knippenberg, A. (1998). The relation between perception and behavior, or how to win a game of trivial pursuit. Journal of Experimental Social Psychology, 74, 865-877.

Dijksterhuis, A., \& van Knippenberg, A. (2000). Behavioral indecision: Effects of self-focus on automatic behavior. Social Cognition, 18, 55-74.

Follenfant, A., Légal, J.-B., Marie Dit Dinard, F., \& Meyer, T. (2005). Effet de l'activation de stéréotypes sur le comportement: une application en contexte sportif [Effects of stereotype activation on behavior: An application in a sport setting]. Revue Européenne de Psychologie Appliquée, 55, 121-129.

Förster, J., Friedman, R. S., Butterbach, E. B., \& Sassenberg, K. (2005). Automatic effects of deviancy cues on creative cognition. European Journal of Social Psychology, 35, 345359.

Gabriel, S., \& Gardner, W. L. (1999). Are there 'his' and 'hers' types of interdependence? The implications of gender differences in collective versus relational interdependence for affect, behavior, and cognition. Journal of Personality and Social Psychology, 77, $642-655$.

Gardner, W. L., Gabriel, S., \& Hochschild, L. (2002). When you and I are 'we,' you are not threatening: The role of self-expansion in social comparison. Journal of Personality and Social Psychology, 82, 239-251.

Gardner, W. L., Gabriel, S., \& Lee, A. Y. (1999). 'I' value freedom, but 'we' value relationships: Self-construal priming mirrors cultural differences in judgment. Psychological Science, 10, 321-326. 
Gibaja, M., \& Mimran, H. (2006). La minute blonde. France: Universal Music France.

Guéro, G., \& Dzack. (2005). Les blondes (Vol. 1-5). Toulon, France: Soleil Productions.

Hannover, B., Pölhmann, C., \& Springer, A. (2005). Implications of independent versus interdependent self-knowledge for motivated social cognition: The semantic procedural interface model of the self. Self and Identity, 4, 159-175.

Hull, J. G., Slone, L. B., Meteyer, K. B., \& Matthews, A. R. (2002). The nonconciousness of Self-consciousness. Journal of Personality and Social Psychology, 83, 405-424.

Kay, A. C., Wheeler, S. C., Bargh, J. A., \& Ross, L. (2004). Material priming: The influence of mundane physical objects on situational construal and competitive behavioral choice. Organizational Behavior and Human Decision Processes., 95, 83-96.

Kühnen, U., \& Hannover, B. (2000). Assimilation and contrast in social comparison as a consequence of self-construal activation. European Journal of Social Psychology, 30, 799-811.

Kühnen, U., \& Oyserman, D. (2002). Thinking about the self influences thinking in general: Cognitive consequences of salient self-concept. Journal of Experimental Social Psychology, 38, 492-499.

Luketic, R. (Writer) (2001). Legally Blonde. In M. Platt \& R. Kidney (Producer). USA: Metro Goldwin Mayer Distribution Co.

Macrae, C. N., \& Johnston, L. (1998). Help, I need somebody: Automatic action and inaction. Social Cognition, 16, 400-417.

Markus, H. R., \& Kitayama, S. (1991). Culture and the Self: Implications for cognition, emotion and motivation. Psychological Review, 98, 224-253.

Oyserman, D., Coon, H. M., \& Kemmelmeier, M. (2002). Rethinking individualism and collectivism: Evaluation of theoretical assumptions and meta-analyses. Psychological Bulletin, 128, 2-72. 
Reips, U.-D. (2002). Standards for Internet-based experimenting. Experimental Psychology, 49, 243-256.

Schubert, T. W., \& Häfner, M. (2003). Contrast from social stereotypes in automatic behavior. Journal of Experimental Social Psychology, 39, 577-584.

Stapel, D. A., \& Koomen, W. (2001). I, we, and the effects of others on me: How selfconstrual level moderates social comparison effects. Journal of Personality and Social Psychology, 80, 766-781.

Stapel, D. A., \& Van der Zee, K. I. (2006). The Self Salience Model of Other-to-Self Effects : Integrating Principles of Self-Enhancement, Complementarity, and Imitation. Journal of Personality and Social Psychology, 90, 258-271.

Trafimow, D., Triandis, H. C., \& Goto, S. G. (1991). Some tests of the distinction between the private self and the collective self. Journal of Personality and Social Psychology, 60, 649-655.

Trivial Pursuit. (1993). Junior Edition. Le Bourget du Lac, France: Hasbro France.

Van Baaren, R. B., Maddux, W. W., Chartrand, T. L., de Bouter, C., \& Van Knippenberg, A. (2003). It takes two to mimic: Behavioral consequences of self-construals. Journal of Personality and Social Psychology, 84, 1093-1102.

Wheeler, L., \& Suls, J. (2007). Assimilation in social comparison: can we agree on what it is? International Review of Social Psychology, 1, 31-51.

Wheeler, S. C., DeMarree, K. G., \& Petty, R. E. (2005). The Roles of the Self in Priming-toBehavior Effects. In A. Tesser, J. V. Wood \& D. A. Stapel (Eds.), On building, defending and regulating the self: A psychological perspective (pp. 245-271). New York, NY, US: Psychology Press. 
Wheeler, S. C., Jarvis, W. B. G., \& Petty, R. E. (2001). Think unto others: The selfdestructive impact of negative racial stereotypes. Journal of Experimental Social Psychology, 37, 173-180.

Wheeler, S. C., \& Petty, R. E. (2001). The effects of stereotype activation on behavior: A review of possible mechanisms. Psychological Bulletin, 127, 797-826. 
Authors Note

The authors thank Olivier Corneille, Caroline Leygue, Francois Ric, and Bo Sanitioso for their precious comments on a previous version of this paper. We also thank the Social Psychology Lab of the Haute-Bretagne University (LAUREPS) that helped running the second experiment of this paper. 


\section{Footnotes}

1. As expected, our variables did not have any effects on other blocks of questions (i.e., easy, moderately easy and difficult questions).

2. Because of the primes (i.e. blondes and men) we controlled for gender. No effect involving gender was significant.

3. As in Study 1, only moderately difficult questions were sensitive to our manipulations.

4. Symmetrically with Study 1, we controlled for gender. Again, no effect involving gender was significant.

5. We thank an anonymous reviewer for outlining this contribution of our paper. 
Table 1

Mean number of correct answers as a function of self-construal and category, Study 1.

\begin{tabular}{cccccc}
\hline & \multicolumn{2}{c}{ Independent self-construal } & & \multicolumn{2}{c}{ Interdependent self-construal } \\
\cline { 2 - 3 } \cline { 5 - 6 } Category & $\mathrm{M}$ & $\mathrm{SD}$ & & $\mathrm{M}$ & $\mathrm{SD}$ \\
\hline Blonde & $1.90_{\mathrm{a}}$ & 1.29 & & $1.14_{\mathrm{b}}$ & 0.86 \\
Control & $1.50_{\mathrm{a}}$ & 0.73 & & $1.93_{\mathrm{a}}$ & 1.11 \\
\hline
\end{tabular}

Means that do not share subscripts differ at $p<.05$

Table 2

Mean number of correct answers as a function of self-construal and stereotype priming,

Study 2.

\begin{tabular}{cccccc}
\hline & \multicolumn{2}{c}{ Independent self-construal } & & \multicolumn{2}{c}{ Interdependent self-construal } \\
\cline { 2 - 3 } \cline { 5 - 6 } Stereotype & $\mathrm{M}$ & $\mathrm{SD}$ & & $\mathrm{M}$ & $\mathrm{SD}$ \\
\cline { 2 - 3 } Blonde & $2.37_{\mathrm{a}}$ & 0.96 & & $1.52_{\mathrm{b}}$ & 0.90 \\
No prime & $1.53_{\mathrm{c}}$ & 0.94 & & $2.17 \mathrm{~d}$ & 0.73 \\
\hline
\end{tabular}

Means that do not share subscripts differ at $p<.05$ 